\title{
Cavity-backed Resistance-loaded Monopole Antenna for Impulse Radar
}

\author{
Mitsuo TAGUCHI*, Ryo YAMANE, Yoichi TOGUCHI**, \\ Takafumi FUJIMOTO, Kazumasa TANAKA \\ Dept. of Electrical \& Electronic Eng., Nagasaki University \\ 1-14 Bunkyo-machi, Nagasaki-shi, 852-8521, Japan \\ ** Information Technology Research Center, Omron Corporation \\ 134 Yokohama Business Park, Godo-cho, Hodogaya-ku, Yokohama-shi, \\ 240-0005 Japan
}

\section{Introduction}

An antenna must operate effectively over a wide range of frequencies and have the reduced ringing within the antenna structure in many applications, such as the impulse radar which transmit and receive impulse signal. For the ground penetrating radar antenna, a T-bar fed slot antenna has suitable characteristics such as wide-band operation, low multiple reflection without absorber [1], [2]. However, the dimension of this antenna is not small compared with the wavelength at the center frequency. The cavity-backed monopole antenna is relatively small and used for the impulse radar [3].

In this paper, the cavity-backed resistance-loaded monopole antenna is analyzed and its broadband operations of input impedance and radiation characteristics arc cxamincd. In the numcrical analysis, the electromagnetic simulator "Fidelity" based on the finite-difference time-domain (FDTD) method is used [4]-[6].

\section{Structure of resistance-loaded monopole antenna}

Figure 1 shows the structure of cavity-backed resistance-loaded monopole antenna. The monopole antenna is located within a rectangular cavity of $\mathbf{C x}=$ $48 \mathrm{~mm}$ by $\mathrm{Cy}=44 \mathrm{~mm}$ by $\mathrm{Cz}=44 \mathrm{~mm}$ in dimensions. The conducting plate $30 \mathrm{~cm}$ by $30 \mathrm{~cm}$ in size is attached at the aperture of cavity. In order to improve the impedance characteristics in the wide frequency range, the planar monopole antenna is adopted. The resistance $R$ is loaded between the top of monopole and the wall of cavity for reducing ringing within antenna structure. In the numerical analysis, the perfectly matched layer of six-layer and fourth-order is used as the absorbing boundary condition. Space steps are from $1 \mathrm{~mm}$ to $4 \mathrm{~mm}$ 
(non-uniform mesh). The calculation region is $140 \mathrm{~mm}$ by $130 \mathrm{~mm}$ by $136 \mathrm{~mm}$ in dimensions. The resistor is replaced to a conducting material with conductivity o such as [7],

$$
\sigma=\frac{\Delta z}{R \Delta x \Delta y}
$$

where, $\Delta x, \Delta y$ and $\Delta z$ are the space steps in the $x, y$, and $z$-direction, respectively.

\section{Numerical and experimental results}

Figure 2 show the input impedance characteristics of antenna. The width of monopole is $W=24 \mathrm{~mm}$. The loaded resistance is $100 \Omega$ or $220 \Omega$. The calculated input impedances agree well with the measured data. Figure 3 show the calculated input impedance characteristics for $W=36 \mathrm{~mm}$. Figure 4 shows the directivity characteristics for $W=24 \mathrm{~mm}$ and $W=36 \mathrm{~mm}$. Figure 5 and 6 show the electric field radiation patterns in the $x z-$ and yz-plane, respectively. When $\mathrm{W}=36 \mathrm{~mm}$ and the resistance $\mathrm{R}=68 \Omega$, the input impedance characteristics show the broadband operation for $0.5 \mathrm{GHz}$ to $4.5 \mathrm{GHz}$.

\section{Conclusion}

The cavity-backed resistance-loaded planar monopole antenna has been analyzed and its broadband operation has been shown for the frequencies from $0.5 \mathrm{GHz}$ to $4.5 \mathrm{GHz}$. The time response of this antenna for the impulse excitation will be shown in the next opportunity.

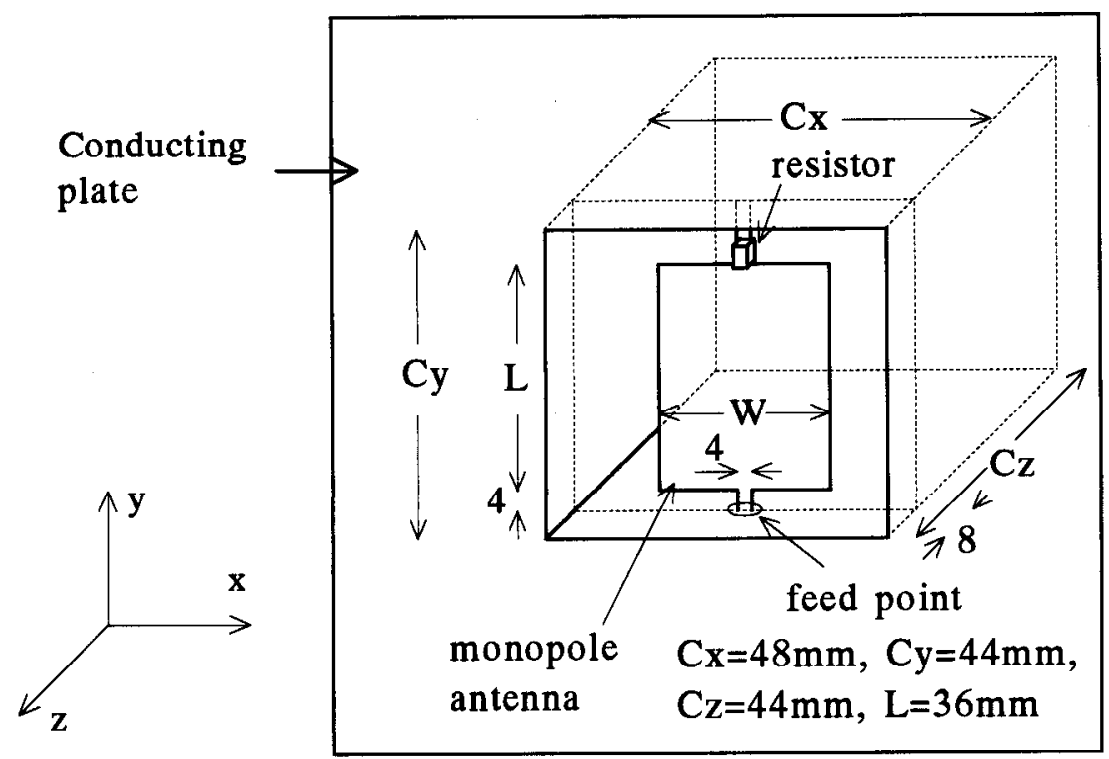

Fig. 1 Cavity-backed resistance-loaded monopole antenna 

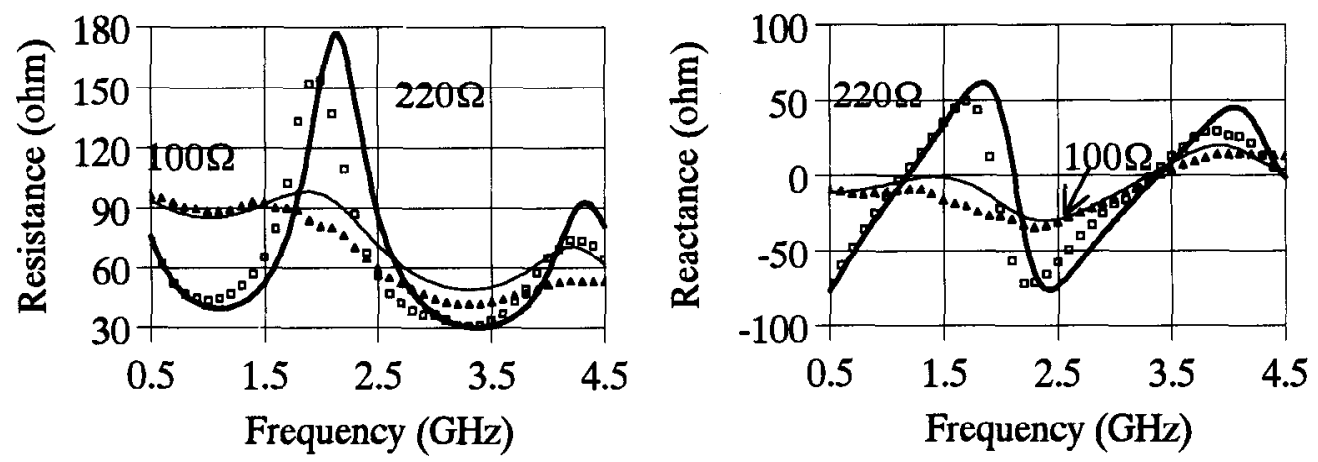

Fig. 2 Input impedance characteristics. $W=24 \mathrm{~mm}$
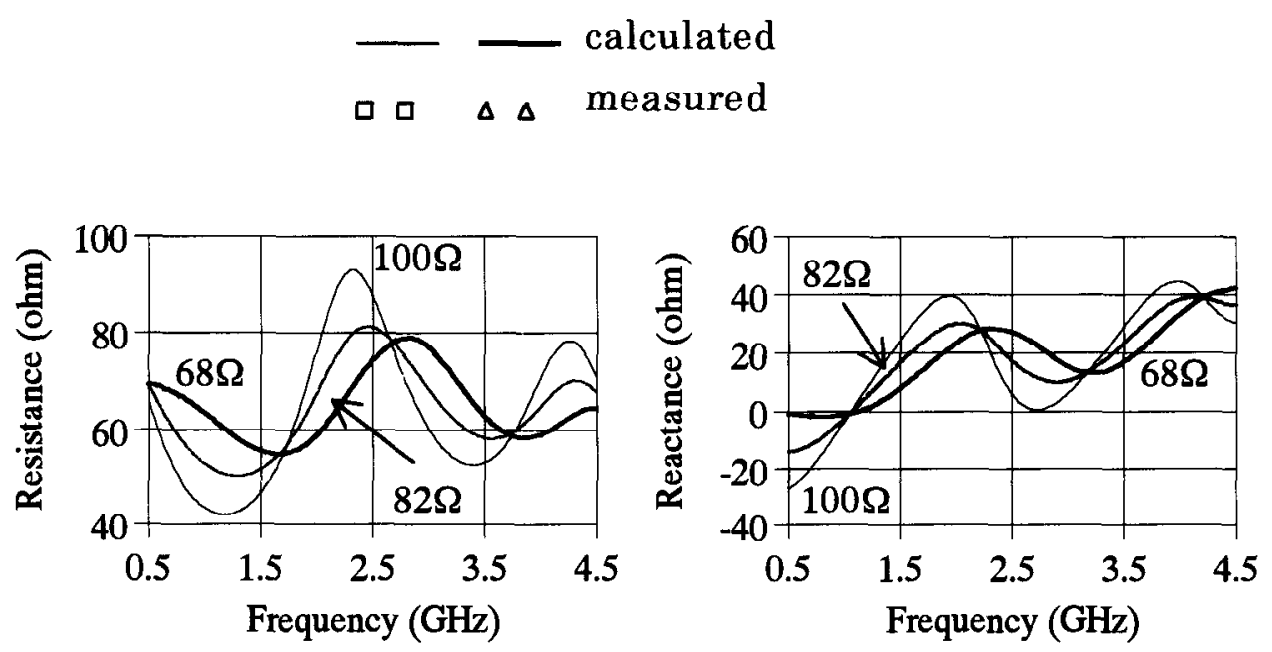

Fig. 3 Calculated input impedance characteristics. $W=36 \mathrm{~mm}$,

\section{References}

[1]E. H. Newman and G. A. Thiele: "Some important parameters in the design of T-bar fed slot antenna", IEEE Trans., Antennas and Propagat., vol.AP-23, pp.97-100, Jan. 1975.

[2]Y. Wakita, H. Yamada, and Y. Yamaguchi: "Surface clutter suppression of the T-bar fed slot antenna", IEICE Technical Report, no.AP98-121, Dec. 1998.

[3]T. E. McEwan: "Impulse radar with swept range", United States Patent, no.5,805,110, Sept. 1998.

[4]K. S. Yee: "Numerical solution of initial boundary value problems using Maxwell's equations in isotropic media", IEEE Trans. Antennas and Propagat., vol.AP-14, pp.302-307, May 1966. 


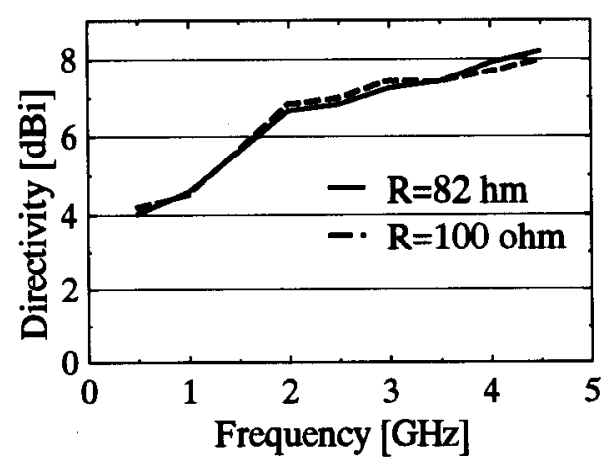

(a) $\mathrm{W}=24 \mathrm{~mm}$

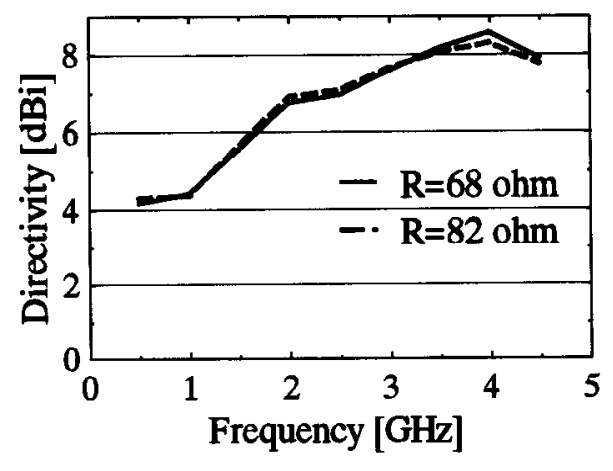

(b) $\mathrm{W}=36 \mathrm{~mm}$

Fig. 4 Calculated directivity characteristics.
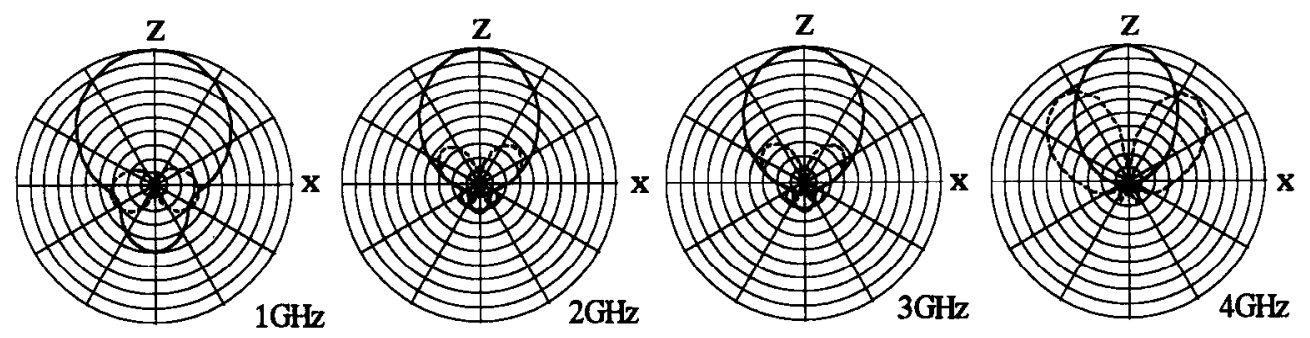

Fig. 5 Calculated electric field radiation patterns in xz-plane.

$\mathrm{W}=36 \mathrm{~mm}, \mathrm{R}=68 \Omega$

- $\phi$ component ---- $\theta$ component
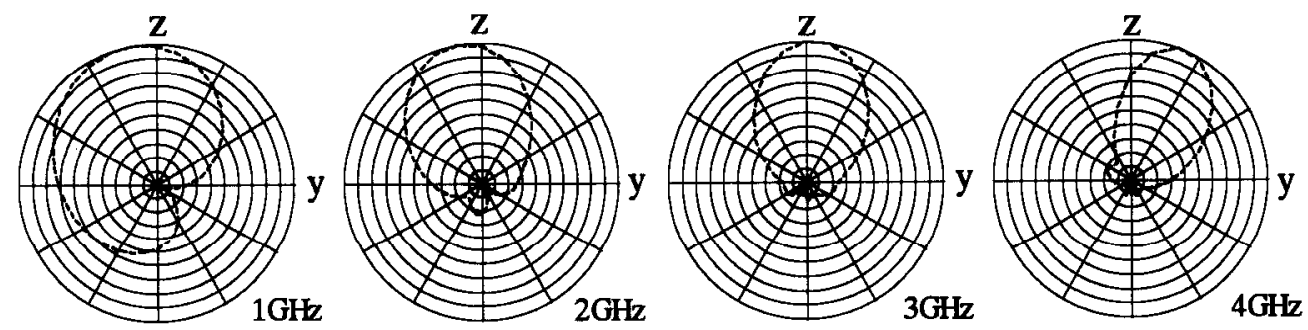

Fig. 6 Calculated electric field radiation patterns in yz-plane.

$$
\mathrm{W}=36 \mathrm{~mm}, \mathrm{R}=68 \Omega
$$
$\theta$ component

[5]A. Taflove: "Computational Electrodynamics The Finite-Difference TimeDomain Method", Artech House, Boston, MA, 1995.

[6]"Fidelity user's manual, Release 1.2", Zeland software Inc., May 1998.

[7]A. Taflove: "Advances in Computational Electromagnetics The FiniteDifference Time-Domain Method”, Artech House, Boston, MA, 1998. 